\title{
Fetal Heart Rate Deceleration Patterns will be Replaced by Numeric Deceleration Data
}

\author{
Kazuo Maeda* \\ Honorary professor, Obstetrics Gynecology, Tottori University, Japan
}

Received: 眥 August 09, 2018; Published: 眥 August 13, 2018

*Corresponding author: Kazuo Maeda, Honorary professor, Obstetrics Gynecology, Tottori University, Japan

Abstract

Subjective pattern classification will be changed to numeric and objective hypoxia index, which prevents cerebral palsy, and objective deceleration area. which predicts neonatal acidemia, particularly in computrized fetal monitoring.

\section{Introduction}

A 50 minutes repeated late decelerations (LD) was followed by highly depressed Apgar 3 neonate, while 3 connected LD cases developed normal vigorus Apgar 9 neonate despite of reports on its ominous outcome [1].

\section{Methods and Results}

The author found that LD is ominous by its frequent repetition , but not by its particular deceleration shape, and created a novel "hypoxia index", which was the sum of duration (min) of all fetal heart rate deceleraions (transient bradycardia) divided by the lowest fetal heart rate (bpm), and multiplied by 100, in fetal heat rate monitoring, where the deceleration pattern classification into early, late and variable decelerations have been used since 1968 by Hon to diagnose fetal distress in fetal monitoring [1]. The author calculaed novel hypoxia index in fetal heart rat curve recorded in the labor, where the author found that the index was 25 or more in all of 6 cases who were diagnosed as infantile cerebral palsy, while the index was 24 or less in all of 16 cases of no cerebral palsy, namely, cerebral palsy is prevented, if hypoxia index is kept below 24 during delivery [2].

In addition, cerebral palsy is able to be treated in very early stage in the neonates whose fetal hypoxia index was 25 or more. Furthermore, an LD is treated by its disappearing after changing maternal supine posture to lateral one in LD case [3], because the LD developed by the loss of placental blood flow due to the compression of pelvic artery by contracted uterus. The lateral posture is recommended to reject LD. Cahill et al reported high deceleration area predicted low umbilical cord blood pH (acidemia), of which presence diagnosed fetal hypoxia [4], while the acidemia and low neonatal Apgar score were predicted by high FHR score even in the 1st stage of birth, which was created by the author [5].

\section{Conclusion}

Intrapartum fetal hypoxia, related to infantile brain damage, is prevented by keeping numeric hypoxia index at 24 or less level, covering all of fetal heart rate decelerations as well as continuous bradycardia, and neonatal acidemia is predicted by deceleration area, expecting the use of numeric indices instead of subjective visible diagnosis of deceleration patterns, particularly in computeterized fetal monitoring.

\section{References}

1. Hon EH (1968) An Atlas of Fetal Heart Rate Patterns. Harty Press, New Haven, Connecticut, US pp. 305.

2. Maeda K, Utsu M (2018) Cerebral Palsy caused by Intrapartum Fetal Damage is Prevented by the Hypoxia Index. Open Access J of Gynecology \& Obstetrics 1(1): 13-21.

3. Poseiro JJ, Mendez Bauer C, Caldeyro Barcia R (1969) Effect of uterine contractions on maternal blood flow through the placenta. Perinatal factors affecting human development, Paho Advisary Committee pp. 161-171.

4. Cahill AG, Tuuli MG, Stout MJ (2018) A prospective study of fetal heart rate monitoring; deceleration area is predictive of fetal acidemia. Am J Obstet Gynecol 218(5): 523.

5. Maeda K, Noguchi Y, Matsumoto F, Nagasawa T (2006) Quantitative fetal heart rate evaluation without pattern classification: FHR score and artificial neural network analysis. In Kurjak, Chervenak (Eds.). Textboook of Perinatal Medicine, (2 $2^{\text {nd }}$ Edn.); Informa, London, Uk, pp. 1487-1495. 


\section{ISSN: 2574-1241}

DOI: 10.26717/BJSTR.2018.07.001577

Kazuo Maeda. Biomed J Sci \& Tech Res

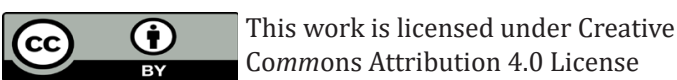

Submission Link: https://biomedres.us/submit-manuscript.php

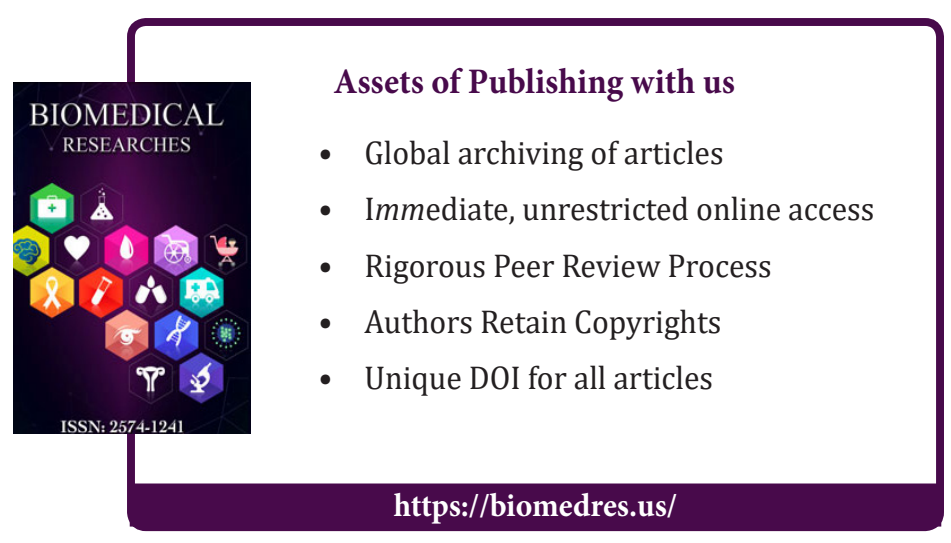

